\title{
Towards a culture of learning: A European policy perspective
}

\author{
Edwin Webb \\ School of Education \& Training
}

\section{Preliminary note}

Two of the most important education and training policies developed (and still being developed) by the European Commission (EC) are those of the Validation of Non-formal and Informal Learning and a Learning Outcomes approach to the specification of learning. Both of these policies are intended to contribute to the achievement of a Lifelong Learning culture within the community. This short article is based upon a half-day training session delivered to officers of the EC (Brussels, October, 2008) and the follow-up summary paper.

\section{Introduction}

The essential context for this seminar, and the themes explored, were provided by the EC Communication, Making a European Area of Lifelong Learning (November, 2001). Achieving the objectives of a lifelong learning policy requires the creation of 'a culture of learning' in which all forms of learning are valued:

'Creating a culture of learning requires that the question of how to value learning in formal, non-formal and informal settings, must be addressed in a coherent way. Enabling citizens to combine and build on learning from school, university, training bodies, work, leisure time and family activities presupposes that all forms of learning can be identified, assessed and recognised.'

The same EC document defines the three forms of learning in the following terms:

- Formal learning is typically provided by education or training institutions, structured (in terms of learning objectives, learning time or learning support) and leading to certification. Formal learning is intentional from the learner's perspective.

- Non-formal learning is not provided by an education or training institution and typically it does not lead to certification. However, it is structured, in terms of learning objectives, learning time or learning support. Non-formal learning is intentional from the learner's point of view. Informal learning results from daily activities related to work, family or leisure. It is not structured in terms of learning objectives, learning time and/or learning support. Informal learning may be intentional but in most cases, it is non-intentional (or incidental/random).

Informal learning may be more familiar to some as 'experiential learning' - learning through and from experience. The EC definitions, though, rest upon discrimination between the 'settings' within which learning takes place, and in given instances such distinctions are arguably nominal rather than absolute. Nonetheless, the EC recognition of non-formal/informal learning, in addition to traditional formal 
statements of learning attainments, represented a significant policy shift in the potential value of all forms of learning. This value was further strengthened with the European Council Draft Conclusions on non-formal and informal learning (May, 2004) which set out Common European Principles 'to encourage and guide the development of high quality, trustworthy approaches and systems for the identification and validation of non-formal and informal learning.'

In brief, the attempt to develop a culture of learning is seen as incomplete without the acknowledgement of the value of learning derived from other than formal processes of traditional education and training. Emerging as the principal means of identifying and recognising such learning is the development of a learning outcomes approach. Here, the recent shift of language (and conception) from 'learning objectives' to 'learning outcomes' is significant. An objective indicates the point to which learning is directed; an outcome details the result of a learning process - whether or not defined in advance. The development of a learning outcomes approach to the recognition and assessment) of learning has become seen as the answer to 'the question of how to value learning in formal, non-formal and informal settings... in a coherent way' (EC, 2001).

The recognition of non-formal/informal learning via a learning outcomes approach, if applied in practice, has considerable potential to change national approaches to education and training. Both policies take further the principled statements relating to the entitlement of the individual to engage in lifelong learning in order to pursue the objectives of 'active citizenship, personal fulfilment and social inclusion as well as employment-related aspects' (EC, 2001).

The notion of life-wide learning (EC, 2001) proposes that learning, in general terms and in vocationally-relevant ways, may result from all forms of learning (formal, non-formal, informal) including learning embedded in social, personal, and vocational experience. The promotion of life-wide learning forms an essential drive within the practical development of lifelong learning. The recognition (which may include certification) of non-formal and informal learning is a critical process towards the implementation of life-wide learning policies. The latest Council of the European Union and Commission joint progress report (Brussels, January 2008, Annex 1) shows that the UK, whilst in the process of 'developing' such systems, does not yet have in place strategies, frameworks, validation systems or national targets for the validation of non-formal and informal learning.

\section{Non-formal/informal learning}

The recognition of non-formal/informal learning can serve a variety of purposes, including:

- To provide a 'second-chance' to achieve qualifications via an alternative route

- To supply a means of addressing skills shortages

- To update vocational/professional needs

- To provide qualifications in their own right or as units towards or exemptions from recognised qualifications

- To promote lifelong/life-wide learning

- To address social factors (disadvantaged/excluded, unemployed, older citizens...). 


\section{Validation of non-formal/informal learning}

Whilst nomenclature varies across national systems and, indeed different meanings can attach to the use of the same term, validation is best and most simply understood as the inclusive term for these three processes:

- Identification of learning ('what has been learned')

- Assessment and/or testing of learning

- Recognition (or results) of various kinds.

Identification makes visible and records the individual's learning outcomes or achievements. A range of methods may be used to identify learning which is often tacit. Such methods include structured interviews, direct observation of the individual's competences, the mapping of personal learning needs. Emerging as one of the most widespread practices is the creation, by the individual, of a portfolio or dossier of various materials targeted at demonstrating specified knowledge, skills, and competences.

Assessment of non-formal/informal learning is essential if recognition is to take the form of certification. It is also a key means by which comparability with similar national awards gained through formal learning can be established.

Recognition, following that assessment, can take various forms, including, among others: certification/part-certification, exemption from part or parts of an educational or vocational qualification, appointment or promotion to a given post.

\section{Some points for discussion}

1. The EC document (2001) 'presupposes that all forms of learning can be identified, assessed and recognised.' It also states that 'a comprehensive new approach to valuing learning is needed to build bridges between different learning contexts and learning forms ...' What measures have to be put in place, within systems, in pursuit of these principles?

2. How do you counter the argument that validation of non-formal/informal learning does not lead to 'proper' qualifications? - that is, certificates of the same value as those gained exclusively through formal learning. And in the particular case where the same awards can be gained either through formal or non-formal/informal means, how do you achieve parity of esteem between these routes?

3. The EC document also states that 'a comprehensive approach to valuing learning is needed to facilitate individual pathways of learning' (EC, 2001). What changes are required, and what are the difficulties posed, in order to enable learners to develop and pursue such individual approaches to learning - especially in the case of awards currently available only through formal patterns of learning?

\section{Learning outcomes}

The development of a learning outcomes approach to education and training is not new; it has existed in some national systems for some years. But the potential of a learning outcomes approach, 
Towards a culture of learning: A European policy perspective

in relation to developing lifelong/life-wide learning and providing a surer basis for the validation of non-formal/informal learning, is generally of more recent recognition.

\section{Questions of definition}

At its simplest, a learning outcome is a definition or description of learning either achieved or to be achieved, stated variously in terms of knowledge, understanding, skills, and competences - or in combinations of these. Again, there is variation from system to system: what, for example, is taken to be a competence in one system may be regarded as a skill (or set of skills) in another. Connected with learning outcomes are related matters of levels (of achievement) and standards (e.g. vocational competence to practice). The essential value of a learning outcome, however, is that it provides an explicit and external statement of learning. In so doing it provides a reference point to which all learning (formal, non-formal/informal) can be directed.

\section{Applications of learning outcomes}

Learning outcomes can be applied at any level as descriptors of learning. They can be used:

- To define, in general terms, a framework for the overall learning achievements for national qualifications (certificates, diplomas, degrees, vocational/professional awards)

- To define the learning to be achieved in a formal programme (or course or unit) of study or training

- To provide statements of knowledge/understanding/skills/competences against which nonformal/informal learning can be assessed

- To make transparent, to both learner and teacher/trainer/assessor, what is to be tested

- To provide means of creating assessment activities derived from statements of learning outcomes for the purposes of testing and/or assessing - so that methods of testing can be seen as both relevant and appropriate.

Additionally, the adoption of learning outcomes can be used to structure each teaching/training session as statements of the learning to be achieved within or by the end of each session (known as specific learning outcomes).

\section{A paradigm shift?}

The adoption of a learning outcomes approach, depending on the point of view generated from within a given European national system, may be simply evolutionary or radically revolutionary. For some, the adoption provides opportunities to apply its principles more widely across all forms of learning; to others it inverts the traditional (didactic) view of teaching and learning, substituting a different, and more profound, model. In all cases, however, the adoption of a learning outcomes approach:

- Shifts attention to the individual learner

- Makes specific the learning requirements to the learner

- Can make learning visible and allow for a broader range of learning to be recognised

- Facilitates access/transfer to further study/training

- Can create more open and more active learning 
Towards a culture of learning: A European policy perspective

- Challenges teachers/trainers to review methods of teaching

- Poses questions about how learning is assessed

- May require traditional programmes/courses of study/training to become more flexible.

In larger terms, learning outcomes can assist in the development of a European credit transfer system for vocational education and training (VET); can provide the basis for developing National Qualifications Frameworks; and form the basis for the European Qualifications Framework as a 'neutral' reference system.

\section{Points for discussion}

- Will the adoption of a learning outcomes approach actually lead to the valuing of learning? Or will it simply lead to the adoption of a 'new' language?

- Will learning outcomes really make any difference to the ways in which teachers and trainers teach and train?

- By specifying learning in explicit terms, will the adoption of learning outcomes result in more testing to see if the prescribed learning has been achieved? Could there be more and more testing but less and less active learning?

- Could the adoption of a learning outcomes approach actually stop experimentation and innovation in teaching/training practices, because the learning outcomes themselves are designed, policed, and statutorily enforced by regional/national agencies and governments?

\section{Summary}

In a very real sense, the validation of non-formal/informal learning and the adoption of a learning outcomes approach are two policy developments which serve each other. In the context of lifelong learning (pursued through the recognition of life-wide learning opportunities), they are interdependent. The recognition of non-formal/informal learning is, to a large extent, made a practical possibility and achievement through statements of learning outcomes. Learning outcomes identify the learning to be made visible and to be assessed. The adoption of a learning outcomes approach, by focusing on learning itself (achieved or to be achieved), accommodates all forms of learning without discriminating among its different forms.

Some of the points for discussion present challenges to the uncritical application of these policies - because there are dangers. Yet there is also genuine potential offered in both developments. Interplay between these two developments could promote genuine opportunities for both personal and vocational/professional growth and help considerably to realise in practice the principles of lifelong and life-wide learning. In the specific context of vocational education and training (VET), there is the possibility, for example, of developing a portfolio of awards that could encourage the professional progression of vocational teachers and trainers, given that within the UK, there is no established policy for such professional and career development of those teachers and trainers.

\section{Selected readings}

Bjornavold, J. (2008) The Shift to Learning Outcomes. Cedefop Panorama Series. Luxembourg: Office for Official Publications of the European Communities. 
Bjornavold, J. (2008) Validation of Non-Formal and Informal Learning in Europe. Luxembourg: Office for Official Publications of the European Communities.

Council of the European Union (2004) Draft Conclusions of the Council and of the Representatives of the Governments of the Member States Meeting within the Council on Common European Principles for the Identification and Validation of Non-formal and Informal Learning. Brussels: Council of the European Union.

Council of the European Union (2008) Draft Joint Progress Report of the Council and the Commission on the Implementation of the 'Education and Training 2010' Work Programme "Delivering Lifelong Learning for Knowledge, Creativity and Innovation" - Adoption. Brussels:

Council of the European Union, 31 January 2008.

European Commission (2001) Making a European Area of Lifelong Learning a Reality: Communication from the Commission. Brussels: European Commission.

Webb, E. (2007) Recognition and Validation of Non-formal and Informal Learning for VET Teachers and Trainers in the EU Member States. Cedefop Panorama Series. Luxembourg: Office for Official Publications of the European Communities. 